\title{
Developing A Digital Learning Medium Using JQuery Mobile For Vocational High School Students
}

\author{
$1^{\text {st }}$ Hary Suswanto \\ Faculty of Engineering \\ Universitas Negeri Malang \\ Malang, Indonesia \\ hary.suswanto.ft@um.ac.id
}

\author{
$2^{\text {nd }}$ Achmad Mursyidun Nidhom \\ Faculty of Engineering \\ Universitas Negeri Malang \\ Malang, Indonesia \\ nidhom.ft@um.ac.id
}

\author{
$3^{\text {rd }}$ Andika Bagus Nur Rahma \\ Putra \\ Faculty of Engineering \\ Universitas Negeri Malang \\ Malang, Indonesia \\ andika.bagus.ft@um.ac.id
}

\begin{abstract}
This research aimed to develop a digital instructional medium for the subject of Computer Assembly in vocational high schools. This learning medium is intended for the tenth-grade students of Informatics and Communication Engineering. The development process was conducted based on the ADDIE model, including analysis, design, development, implementation, and evaluation. The result of the development was a mobile application containing instructional materials about computer assembly. The app was created with the JQuery Mobile framework for mobile device optimisation. The developed application contains four main menu options, i.e. home, content, quiz, and help.
\end{abstract}

Keywords-Computer Assembly, Mobile Learning, Mobile Application, JQuery Mobile, Digital Learning Medium

\section{INTRODUCTION}

Along with the advancement of technology, there has been an ever-increasing demand for high mobility in the education sector, particularly in learning media. A learning medium is a means to improve students' understanding of learning materials. Given the importance of a learning medium, it is necessary for the development of various kinds of electronic media to facilitate mobility. Computer Assembly is one of the subjects taught in vocational high schools based on the curriculum of 2013. This course consists of both lectures and practical workshops intended for tenth-grade students. In the teaching of this course, the provision of appropriate instructional media is essential. In fact, the sufficiency of media for learning is vital because an instructional medium is a guideline for learners in the learning process [1].

To date, the most frequently used medium for learning is paper or print with limited and static content [2]. In this situation, the development of learning media, in terms of content and media, is of the essence. One way to develop learning media is by using mobile learning. Mobile learning is part of electronic learning or more known as e-learning [1]. Elearning is essentially a form of learning delivered in digital format via information technology [4]. Mobile learning is an application that can be used as a solution to educational problems especially the problem of equitable access to education and quality of learning content and teachers [2].
Electronic media indeed offer a variety of modern features that are expected to provide convenience in the delivery of Computer Assembly lessons.

This study aimed at developing a digital medium for learning the assembly of computers with the use of mobile technology that is able to remedy the shortcomings of existing learning media. The digital learning medium created developed in this research offers a variety of features capable of providing high-quality materials that come with explanations, Fig.s, and tutorial videos. Via mobile technology, the learning materials were expected to be easily accessible and attractive to motivate learners in studying. Also, the learning medium could serve as a set of job sheets completed with working Fig.s, step-by-step instructions and evaluation sheets [3].

A job sheet serves as a guideline for performing hands -on activities in the laboratory. In general, the job sheet aims to guide teachers throughout the instructional process. Also, the job sheet also provides guidance to students in doing practical or laboratory activities and serves as a tool for assessing student achievement/mastery. Job sheets are written in a standard language, clear, simple, communicative and easily understood by students. They also consist of notations and terms that are common and widely used in the school/work environment. Also, job sheets feature illustrations or Fig.s as visual aids for learning the materials.

E-learning plays a significant role in education, but regrettably, it is rarely used [4]. E-learning is an educational system or concept that utilises information technology in teaching and learning process. Not only that, in e-learning, lessons are delivered using electronic or computer systems so as to support the learning process [5]. E-learning refers to distance learning in which principles of the instructional process are integrated with technology. In other words, the teaching and learning process can take place without any faceto-face contact between teachers and students [6].

Another problem is the lack of students' understanding of the benefits of e-learning [7]. One type of e-learning is mobile learning, which is a learning model that utilises information and communication technology. The major advantages of mobile learning are that the instructional materials can be 
accessed easily at any time and are visually attractive [5]. However, not every teaching material is suitable for mobile learning. In this study, the researchers developed an application for mobile learning with the use of JQuery Mobile. JQuery Mobile is a web application framework optimised for responsive viewing especially on mobile devices. This framework consists of CSS and JavaScript libraries intended for the touchscreen display. The JavaScript library in JQuery is modular, supporting the development of dynamic web pages with various features and web-based applications. With all of those favourable elements of the JQuery framework, the development of mobile learning applications can progress.

\section{RESEARCH METHOD}

This research was conducted based on the ADDIE development model comprising Analysis, Design, Development, Implementation, and Evaluation. Following the first step, i.e. analysis, the researchers analy sed the educational goals, curriculum and materials, users' ability level and their characteristics. This stage aimed at identifying the curriculum and materials to be learned by the users so that the developed application could accommodate their learning needs. Second, the researchers designed the items to be presented, material manuscripts, and flow of material delivery in the form of flowchart and media storyboard as well as collected all materials needed. The next stage was the development process involving the JQuery Mobile framework. Following the framework, the application modules were composed using an editor called Sublime Text. After all modules were completed and integrated, the application was built using Ionic SDK. The resulting application was in the form apk or android package that could be installed on all Android devices. This learning medium, in fact, can be run anytime and anywhere, and hence facilitating students in learning due to its easy access.

The next stage was the implementation process involving 20 respondents, done to determine user satisfaction and attitude towards the developed application. The results of this step would be the basis for determining the validity of the application, and hence the evaluation stage. The product was assessed for its quality based on user feedback so that any flaws could be identified and fixed. Qualitative and quantitative data were collected through questionnaire. The data taken were information about Computer Assembly lessons, and the learning media and materials used. The equipment utilised for developing the application consisted of a personal computer and software packages. i.e. an editor (Sublime Text), framework (JQuery Mobile 1.4.5), and builder (Ionic SDK).

[1] RESULTS

The final product of this development is a mobile application containing instructional materials about Computer Assembly and developed using the JQuery framework; it can be run as a web application (before being built with SDK) and Android application (after being built with SDK). As a matter of fact, the JQuery Mobile framework is a great tool for making applications optimised for mobile devices. The application developed in this study can be launched on either Android smartphones and tablets or Windows computers or laptops. The minimum requirements to run this application on mobile devices are presented in Table 1.

T ABLE 1. MINIMUM REQUIREMENT SFOR T ABLET SOR SMARTPHONES

\begin{tabular}{|l|l|}
\hline Component & \multicolumn{1}{|c|}{ Minimum Requirement } \\
\hline Processor & MTK 6572 Dual-Core1 GHz \\
\hline Screen Resolution & $512 \mathrm{MB}$ \\
\hline RAM & $540 \times 960$ pixel \\
\hline Operating System & Jelly Bean (Android4.2.2) \\
\hline GPU & Mali-400MP \\
\hline
\end{tabular}

Also, the minimum system requirements for running the application on a Windows computer or laptop are presented in Table 2.

T ABLE 2. MINIMUM SYSTEM REQUIREMENT SFOR DESKT OPS OR LAPTOPS

\begin{tabular}{|l|l|}
\hline Component & \multicolumn{1}{|c|}{ Minimum Requirement } \\
\hline Processor & $\begin{array}{l}2.33 \mathrm{GHz} \text { or faster x 86-compatible processor or } \\
\text { Intel Atom } \\
\\
\text { netbooks } 1.6 \mathrm{GHz} \text { or faster processor for }\end{array}$ \\
\hline Operating System & Windows 7 starter \\
\hline RAM & $1 \mathrm{~GB}$ \\
\hline Browser & edge, mozilla, chrome, opera (newest browser) \\
\hline
\end{tabular}

This application presents several course materials, including assembly tools and materials, place and work safety, dissambly procedures, and bios configuration. The subject matters will continue to be added and updated to adapt the development of curriculum. In this application, there are four main menu options. The first one is the "Home" menu that contains the start page of the application and a brief description of the topic of discussion. It is presented in Fig. 1.

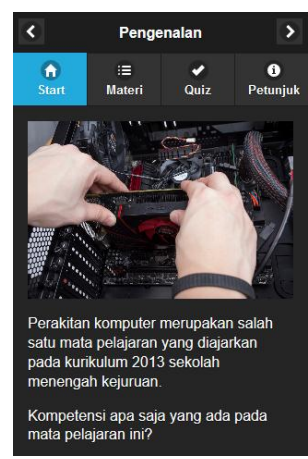

Fig. 1. Start page (home)

Fig. 1 shows that the menu of materials is the core menu of this application, containing the choices of the topics to be studied. In this menu, the materials are also presented in the form of video tutorials that can be accessed online. See Fig. 2. 


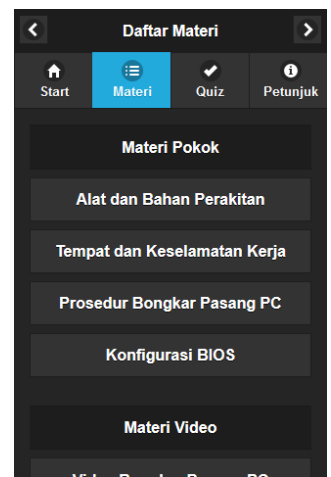

Fig. 2.Menu of Materials

Each topic contains several explanation panels designed with a collapsible feature and is equipped with Fig.s and captions that can be enlarged (as shown in Fig. 3).
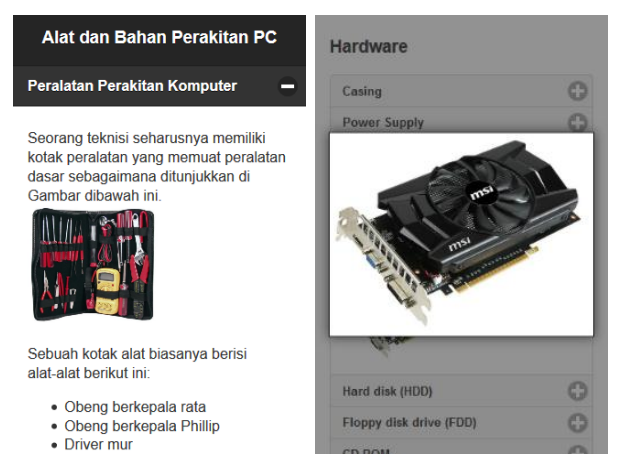

Fig. 3. Topic contents

After learning a certain topic, users can test their understanding with quizzes. They can go to the "Quiz" menu, select the topic and take the quizzes in the form of multiplechoice questions. See Fig. 4.

Fig. 4. Quiz menu
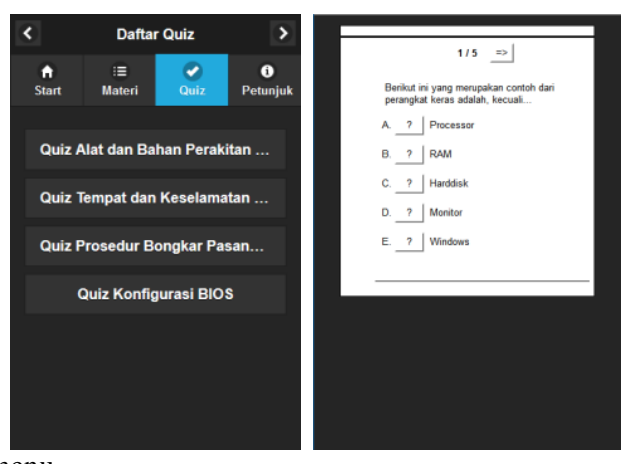

The last menu "Help" contains instructions for using the application such as navigation and access to materials and quizzes and information about the developers. This menu aims to help users who have difficulty in using the application. See Fig. 5.
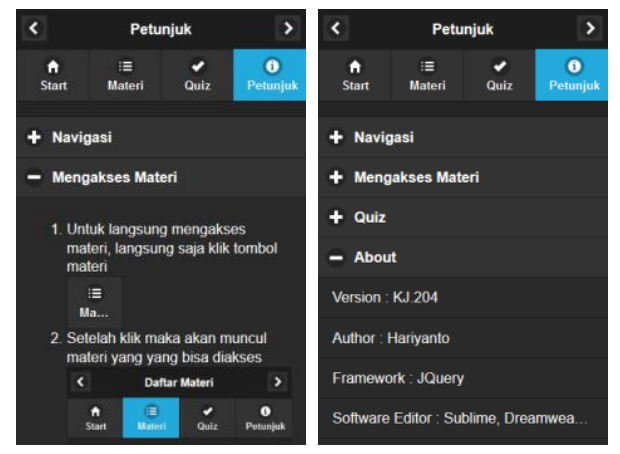

Fig. 5. Help menu

\section{DISCUSSION}

The learning medium developed in this study is a mobile application that uses the JQuery Mobile programming language and can run on mobile devices. Therefore, it can be accessed anytime and anywhere. The application is classified as a medium for mobile learning. Mobile learning is a learning process in which users are not required to stay in one place to learn, or in other words the learning activity occurs with the use of technology with high mobility [2].

This application consists of four main menu items. The "Home" menu shows the first page of the application and the introduction of the course. The "Help" menu contains instructions for using the application. The "Content" menu presents the materials of Computer Assembly course. The "Quiz" menu provides quizzes in the form multiple choice questions to check or assess understanding.

The results of product field trial involved 38 students Universitas Negeri Malang indicate that the learning mediu developed is applicable to use since it has satisfied the criter of a good-quality learning medium. Also, the survey on th suitability of the materials showed favourable results, $i$. $28.9 \%$ respondents gave a $5,42.1 \%$ gave a 4 , and $28.9 \%$ gave 3. See Fig. 6.

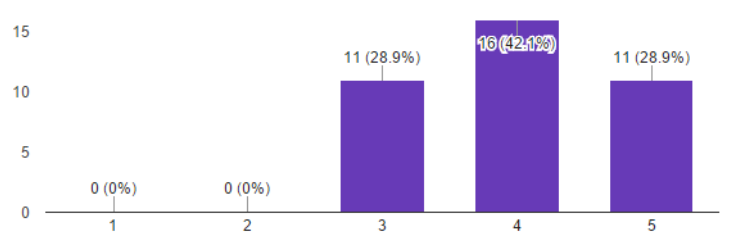

Fig. 6. Results of Survey on the Suitability of Materials

The results of the survey on language use showed that $23.7 \%$ respondents gave a $5,31.6 \%$ gave a 4 , and $44.7 \%$ gave a 3. The results are presented in Fig. 7.

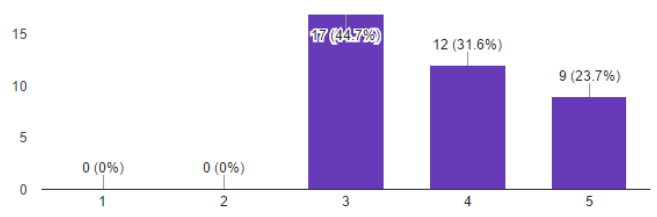

Fig. 7. Results of Survey on the Effectiveness of the Language Used 
According to the survey results of the display effectiveness, $28.9 \%$ respondents gave a $5,44.7 \%$ gave a 4 , and $26.3 \%$ gave a 3. The results are shown in Fig. 8 .

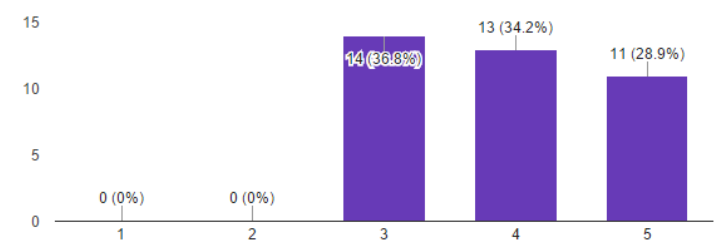

Fig. 8. Results of Survey on the Display Effectiveness

The survey on the reliability of videos showed positive results, i.e. $28.9 \%$ respondents gave a $5,34.2 \%$ gave a 4 , and $36.8 \%$ gave a 3. See Fig. 9 .

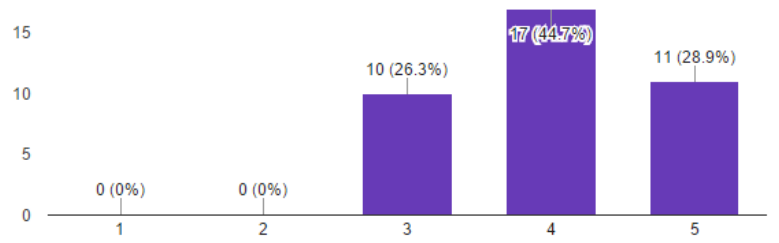

Fig. 9. Results of Survey on the Reliability of Videos

As shown in Fig. 10, the survey results on the accuracy in writing showed that $21.1 \%$ respondents gave a $5,47.4 \%$ gave a 4 , and $31.6 \%$ gave a 3 .

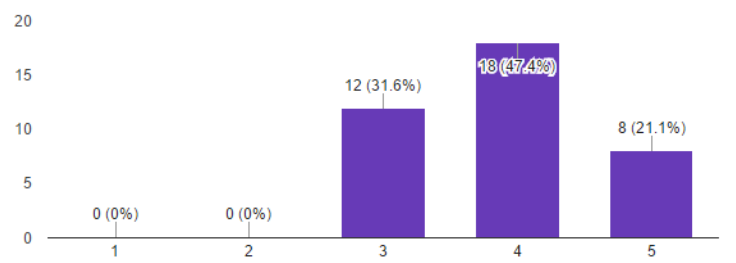

Fig. 10. Results of Survey on Accuracy in Writing

The results of the survey on the suitability of materials showed that $23.7 \%$ respondents gave a $5,36.8 \%$ gave a 4 , $36.8 \%$ gave a 3 , and $2.6 \%$ gave a 2 . See Fig. 11 .

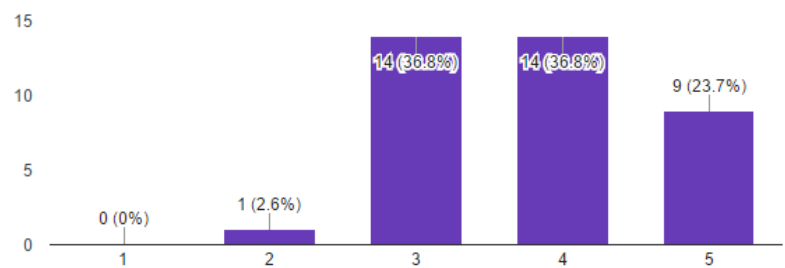

Fig. 11. Results of True-Survey
The results of the survey on the suitability of materials showed that $26.3 \%$ respondents gave a $5,47.4 \%$ gave a 4 , and $26.3 \%$ gave a 3 . These results are presented in Fig. 12 .

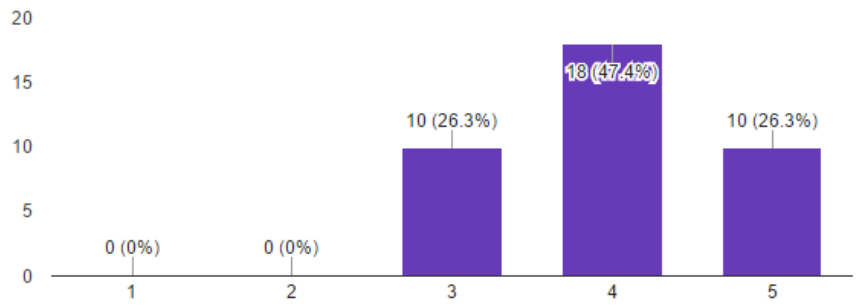

Fig. 12. Results of Survey on the Product Attractiveness

The application developed in this research can run on various mobile devices because it was developed using the JQuery Mobile framework. However, this application has several drawbacks such as incomprehensive contents and inattractive layout and design. Therefore, future research is expected to develop similar applications that have more indepth contents and engaging display. Also, to develop attention-grabbing applications, it is suggested to integrate more multimedia resources as well as interactive elements into the application. The development of more learning applications for mobile devices is expected to promote the benefits of mobile devices in the field of education and provide a positive effect on learning. All in all, the presence of such applications is vital to encourage students to learn more deeply and enjoy the process so that the knowledge gained is not easily forgotten.

\section{CONCLUSIONS}

The product developed in this study is a learning medium in the form of a mobile application. It can be run by students via android devices or personal computers. The application provides learning materials and video tutorials for the Computer Assembly course. It is equipped with assessment instruments in the form of quizzes for each topic. There are four main menu items in the application. The "Home" menu shows the first page of the application and the introduction of the course. The "Help" menu contains instructions for using the application. The "Content" menu presents the materials of Computer Assembly course. The "Quiz" menu provides quizzes in the form multiple choice questions to check or assess understanding.

The learning medium can be operated on various Android mobile devices. It presents instructional materials about computer assembly which are interesting and easy to understand. Also, it is easy to navigate due to the reflowable format. In this application, there are quizzes to test students' understanding, video tutorials to present the materials more clearly, Fig.s to help students understand better. Overall, this learning medium is applicable to use but should be improved further. 


\section{REFERENCES}

[1] A. B. N. R. Putra, W. Irdianto, A. Mukhadis, and S. Suhartadi, "Pocket Book Learning: Leaming Methods to Train Students Productive and Creative Using 'BRANO' as an Effective Learning Recorder,' in Proceedings of the International Mechanical Engineering and Engineering Education Conferences (IMEEEC-2016), 2016, vol. 30034, p. 30034.

[2] H. Suswanto, A. M. Nidhom, A. B. N. R. P. Putra, and J. A. H. Hammad, "Developing An LMS-Based Cross-Platform Web Application For Improving Vocational High School Students' Competitiveness In ASEAN Economic Community," Pendidik. Sains, vol. 5, no. 3, pp. 72-79, 2017.

[3] A. B. N. R. Putra, A. Mukhadis, and S. Suhartadi, "Miskonsepsi Transmisi Mobil dan Pemecahannya Menggunakan Pembelajaran Peta
Pikiran pada Kompetensi Memelihara Transmisi Mobil Siswa SMK," Teknol. dan Kejuru., vol. 38, no. 2, pp. 133-146, 2016.

[4] M. G. Violante and E. Vezzetti, "Virtual interactive e-learning application: An evaluation of the student satisfaction," Comput. Appl. Eng. Educ., vol. 23, no. 1, pp. 72-91, 2015.

[5] S. Mohammadyari and H. Singh, "Understanding the effect of elearning on individual performance: The role of digital literacy," Elsevier Comput. Educ., vol. 82, pp. 11-25, 2015.

[6] A. Mukhadis and U. Nurul, "Prototipe Pembelajaran Terintegrasi Model Shared Berbasis Gallery Project," J. Pendidik. dan Pembelajaran, vol. 21, no. 2, pp. 132-145, 2014.

[7] V.Arkorful and N. Abaidoo, "The role of e-learning, advantages and disadvantages of its adoption in higher education," Int. J. Instr. Technol. Distance Learn., vol. 12, no. 1, pp. 29-42, 2015. 